\title{
Effects of Eco-Driving Training: A Pilot Program in Belgrade Public Transport
}

\author{
Tatjana SAVKOVIĆ, Pavle GLADOVIĆ, Milica MILIČIĆ, Pavle PITKA, Sanja ILIĆ
}

\begin{abstract}
This paper shows an eco-driving pilot program that has been implemented in the public transport company "JGSP Belgrade", Serbia, in order to assess the possibilities of using eco-driving for an entire car fleet of the assessed company in the future. Eco-driving training and education of thirteen drivers were conducted in real driving conditions on the route length of $14 \mathrm{~km}$ and consisted of three phases. The results of eco-driving training of thirteen bus drivers confirm the findings of the previous researches that eco-driving has got many benefits. After the training, all drivers saw fuel consumption reduced by $8.61 \%$ on average, and consequently the average $\mathrm{CO}_{2}$ emission reduced by $8.61 \%$. The implementation of eco-driving training in the assessed company and the attained fuel economy, leads to significant annual savings. However, some driving parameters were not significantly improved after training indicating a driver's slow adaptation and application of new driving techniques.
\end{abstract}

Keywords: bus drivers; $\mathrm{CO}_{2}$ emissions; eco-driving; fuel economy; operating parameters

\section{INTRODUCTION}

Road transport has a negative impact on fuel economy and ecology. In order to identify the factors that influence fuel consumption and $\mathrm{CO}_{2}$ emissions, researchers around the world have developed methods for fuel consumption estimation $[1,2]$ and $\mathrm{CO}_{2}$ emissions estimation in road transport [3]. However, many researchers believe that driver behaviour has a great influence on fuel-use and $\mathrm{CO}_{2}$ emissions [5-7]. Eco-driving program seems like a promising strategy that can positively change the driver's behaviour and improve driving fuel efficiency. In several European countries, eco-driving is applied as a manner to promote economic driver behaviour. In practice, ecodriving has attracted attention among automakers, policy makers, and researchers because its implementation is not expensive and can be cost-effective.

Eco-driving advices are well defined and comprehensible for drivers. They include the following: avoiding harsh stops and starts; anticipating traffic situations, smooth acceleration, using the engine braking, maintaining steady speed, eliminating excessive idling, driving at or below the speed limit. Besides, Barkenbus [8] noted that some eco-driving adherents involve automobile maintenance measures. The recommendation is a monthly tyre pressure checking and regular changing of air filters.

This paper shows ecological and economical advantages of eco-driving dealing solely with driving behaviour. This eco-driving training pilot program for bus drivers is a preliminary step to, possibly, future implementation of eco-driving training program for all drivers in the public transport company "JGSP Belgrade", Serbia. This pilot program should assess the possibility of using eco-driving training in the aforementioned company and its 841 vehicles in the future.

\subsection{Advantages of Eco-Driving Program}

There are numerous advantages of using the ecodriving programs. Primarily, these programs can be connected to safety driving training for existing drivers. Furthermore, the programs can be applied to any vehicle on the road regardless of its age, size and type. The results of eco-driving are visible shortly after their implementation for the entire car fleet. Savings in fuel consumption and reduction of emissions are visible from day one [8].

A study for the bus drivers conducted in Greece showed the potential fuel savings of $10-15 \%$ [9]. Basaric et al. [10] also indicated the positive fuel economy effects of eco-driving on bus drivers. They established it was possible to achieve savings in fuel consumption and $\mathrm{CO}_{2}$ emission by approximately $11,71 \%$. In addition, Ho, Wong and Chang [11] have shown that the eco-driving training had the potential to reduce fuel consumption and $\mathrm{CO}_{2}$ emission by $10 \%$. Rutty, Matthews, Andrey and Del Matto [12] showed the favourable results on the impact of ecodriving training on $\mathrm{CO}_{2}$ emissions in the period immediately after the training, comparing with $\mathrm{CO}_{2}$ emission one month before training. Analysing the vehicle operating parameters such as idling, idle fuel consumption, $\mathrm{CO}_{2}$ emission and harsh acceleration, they determined a reduction in $\mathrm{CO}_{2}$ emission by $1,7 \mathrm{~kg}$ per vehicle per day. In addition, some papers indicated the safety benefits. Namely, Haworth and Symmons [13] in their report indicated a reduction of traffic accidents by $35 \%$ using ecodriving training. SenterNovem [14] showed that the accident damage rate decreased by $40 \%$ after eco-driving training in Germany. Beusen et al. [15] have defined the key safe driving behaviours which represent the basis of eco-driving.

\subsection{Difficulties in Adaptation and Application of Eco- Driving}

For over 15 years, eco-driving has been an initiative with a widespread adoption, but the level of accomplished results and its long-term usage depend on certain limitations. Insufficient exposure of drivers to eco-driving information affects their behaviour and sustainability of the changed driving style over a longer period of time. Barkenbus [8] confirmed that there was a need for more initiatives on eco-driving in order to show positive application results, and to persuade the drivers that they should change their habits and driving style.

Before the implementation of eco-driving, the gaps in the public's limited comprehension of the nature of ecodriving and deeply rooted driving behaviour, should be filled. The researches show that the drivers have a tendency to forget the given instructions during their training, and 
that they fall back to their driving habits. Beusen et al. [15] showed that the majority of drivers made the immediate improvements in fuel consumption after the training, and some drivers had a tendency to return their old driving habits. S. Siero, Boon, Kok and F. Siero [16] noted a decline in positive attitude of the post-office drivers six months after the fuel economy training. However, it should be noted that the driving habits formed through experience are hard to break. Dogan, Steg and Delhomme [17] showed that the eco-driving style could hardly become a driving habit because it depended on certain factors, such as: traffic conditions, environment and personal motives.

Cultural and educational barriers slow the rate of adoption and sustainability of eco-driving from occurring. A study in France, that included 1200 car drivers, showed that despite an intense motivation to reduce fuel consumption, majority of drivers ignored the eco-driving instructions [18]. However, implementation of eco-driving feedback devices in the vehicles could be a good practice that would help the drivers to make a decision when driving. Yang, Li and Zheng [19] showed that these devices have a great role in reduction of $\mathrm{CO}_{2}$ emission and fuel consumption. When utilising these devices, one must take into account the type, complexity, contents and presentation of information from the perspective of ergonomy.

The bus drivers have a difficulty in maintaining a balance among the goals to be achieved. They have to adhere to the bus timetable, on the other hand, need to drive economically. Dogan et al. [17] has shown that performances in fuel economy decline when the drivers have to balance the reduction of fuel consumption and travel time.

Some researchers proposed their solution for the aforementioned problems. Barkenbus [8] believes that the eco-driving should become a norm and suggests the measures, such as regulation, training, education, feedback devices, fiscal stimulus and strengthening of social norms that can be used to influence the driving behaviour of individuals. Sullman, Dorn, and Niemi [20] believe that in order to motivate the drivers to apply the eco-driving principles and improve their driving performances, the transport company should pair up the eco-driving training with the behavioural change techniques. Some researchers suggest that the eco-driving program should be included in the national climate change strategies $[21,22]$. Van den Hoed et al. [21] claim that encouraging professional, individual drivers and fleet owners through eco-drive program to drive in a more ecological way can lead to reduction of $\mathrm{CO}_{2}$ emissions in the transport sector. Also, several IEA countries have included the eco-driving activities as part of their $\mathrm{CO}_{2}$ emission reduction strategies and national climate change programs [22].

\section{RESEARCH METHODOLOGY}

\subsection{Participants}

Eco-driving training was conducted on July 5th, 6th, 12th and 13th, 2016 in the public transport company "JGSP Belgrade", operating in Belgrade, Serbia, and included thirteen bus drivers who voluntarily agreed to be monitored for a period of time. The average age of the participants was 42 , with a standard deviation of 2,62 . The average driving experience was 12 years $(S D=2,19)$. The study participants were selected using purposive sampling.

\subsection{Test Route and Test Vehicle}

In order to eliminate the difference in road conditions for the drivers, training was conducted on the same predetermined route, from the public transport company "JGSP Belgrade" depot in Novi Beograd to the bus 85 last stop in Banovo Brdo. Total length of the route in both directions was around $14 \mathrm{~km}$.

The same bus, MAN SG313 with automatic transmission, was used for each day of testing so that the drivers could drive the same bus each time. It was equipped with a Controller Area Network (CAN) bus enabling the reading of driving parameters. In case of each measurement, the test vehicle parameters that affect fuel consumption were approximately the same.

\subsection{Procedure}

The study was conducted between 9 a.m. and 4 p.m. As an initial hypothesis, approximately the same number of vehicles and network conditions were selected in order to characterise the time periods and the driving behaviour in the tested interval.
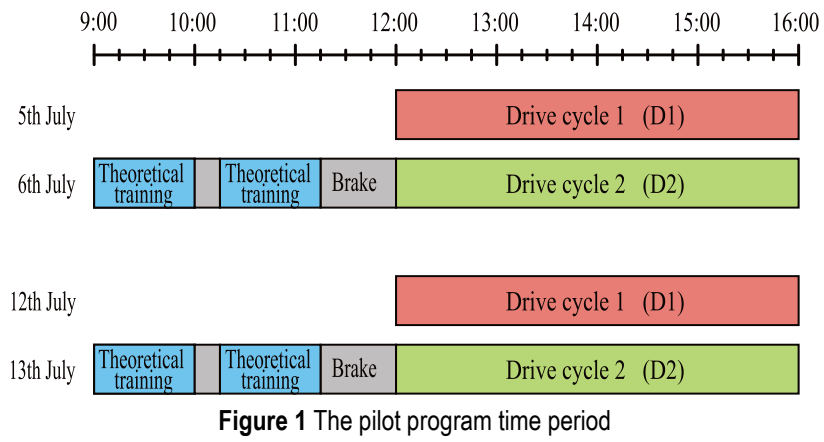

The test drive was taken twice by each driver: first before eco-driving training (normal driving) and second after eco-driving training with the professional eco-driving instructions. Eco-driving training has two sessions; a theoretical approach and a practical driving under instructor. The whole pilot program included three stages (in Fig. 1):

- Before eco-driving training - D1 (Drive cycle 1) - This drive was completed by all the participants in the study so that the driving style could be recorded before the implementation of eco-driving tips. The first seven drivers (driver 1 - driver 7) conducted the initial drive (D1) on 5th July 2016 and the other six drivers (driver 8 -driver 13) on 12th July 2016 between 12 a.m. and 4 p.m. This serves as the control point in comparison to drive cycle 2 (D2) so that the potential fuel economy, advancement in driving and vehicle parameters achieved with eco-driving, can be assessed.

- Classroom training session - Theoretical eco-driving training was undertaken by the licensed instructors from RICo Training Centre (Accredited Training Institute of the World's Road Transport Organisation - IRU from Geneva) in duration of 120 minutes. Classroom training session took place on 6th July 2016 (driver 1 - driver 7) and 13th 
July 2016 (driver 8 - driver 13) before drive cycle 2 . The training program was a static approach which aimed at urging drivers to apply eco-driving techniques after learning. Some of the advices given to the drivers include: driving at the speed limit, slow motion, decelerate smoothly, anticipate traffic flow, maintain a steady speed at low RPM (revolutions per minute) etc.

- $\quad$ Practical driver training - D2 (Drive cycle 2) - Drive cycle 2 combines the techniques learnt during the classroom teachings, as well as the real-time guidance from the instructor during the drive cycles. This drive cycle was conducted on 6th July 2016 (driver 1 - driver 7) and on 13th July 2016 (driver 8 - driver 13) between 12 a.m. and 4 p.m. After the completion of drive cycle 2, the obtained results were presented to drivers in order to evaluate the effects and identify the key needs for future development. The logged parameters are as shown in Tab. 1.

Table 1 List of parameters logged for both drive cycles 1 and 2

\begin{tabular}{|c|c|c|}
\hline Parameter & Unit & Description \\
\hline Duration & hh:mm:ss & From start to end of the drive \\
\hline Distance & $\mathrm{km}$ & Distance covered \\
\hline Average speed & $\mathrm{km} / \mathrm{h}$ & Vehicle speed for the distance travelled in a given period of time \\
\hline Average speed - on the move & $\mathrm{km} / \mathrm{h}$ & $\begin{array}{l}\text { Vehicle speed for the distance travelled in a given period of time when the } \\
\text { vehicle is in motion }\end{array}$ \\
\hline Fuel consumption - on the move & L(litre) & Amount of fuel used while the vehicle is in motion \\
\hline Total fuel consumption & L(litre) & Amount of fuel used during a specific drive \\
\hline Average fuel consumption & $\mathrm{L} / 100 \mathrm{~km}$ & Average amount of fuel used during a specific drive \\
\hline Average $\mathrm{CO}_{2}$ emission & $\mathrm{kg} / 100 \mathrm{~km}$ & Corresponding average $\mathrm{CO}_{2}$ emission for a specific drive \\
\hline Average accelerator pedal position & $\%$ & $\begin{array}{l}\text { Average accelerator pedal position ranges between } 0 \% \text { (not touching) and } \\
100 \% \text { (fully pushed) }\end{array}$ \\
\hline Driving without accelerator pedal - moving time & mm:ss & Vehicle drive time when driving without using accelerator pedal \\
\hline Brake time & mm:ss & Total duration of brake time per drive \\
\hline Driving without accelerator pedal - total distance & $\mathrm{km}$ & Total distance when driving without accelerator pedal \\
\hline Brake usage - total distance & $\mathrm{km}$ & Total distance with brake pedal usage per drive \\
\hline Brake count & - & Total number of braking occurrences per drive \\
\hline Stopping events count & - & Total number of events that affect the vehicle stop \\
\hline Idling time & $\mathrm{mm}: \mathrm{ss}$ & Total duration when vehicle's engine is running and the vehicle is not in motion \\
\hline Gearshift count & - & Total number of gearshifts according to driving style \\
\hline Average engine speed & $\mathrm{rpm}$ & Number of revolutions per minute at which the engine crankshaft turns \\
\hline
\end{tabular}

\subsection{Data Collection}

Data was collected after connecting CAN network with the software Key Driving Training System produced by Belgian company Key Driving Competence, using the diagnostic cable SAE J1939. Using two interfaces (Kvaser and Squarell) the data was translated into computable and readable data that could be used on a PC.

The data collected were statistically evaluated to measure the effectiveness of the Eco-driving training program. Statistical evaluation of the driving parameters was investigated using paired t-test (at 5\% significance level) in statistical program MINITAB 17. Paired t-test was used to compare whether the results of driving parameters after the eco-driving training were significantly improved to the results before training.

\section{RESULTS AND DISCUSSION}

Analysis of the driving quality parameters before (D1) and after eco-driving training (D2) as per Tab. 2 show an average speed deceleration of nine drivers between range of 2,92\% - 14,67\% while four drivers increased the average speed after training between range of $0,73 \%-23,70 \%$. Similar values were obtained in the analysis of the average speed while the vehicle was in motion. The results among thirteen drivers revealed that there was no significant effect of the eco-driving training in both parameters, $p=0,756$ and $p=0,548$, respectively.

After completing the second Drive cycle (D2), and when compared to the test drive before the training (D1), almost all drivers reduced the fuel consumption while the vehicle was still in motion. Driver 2 achieved the least savings in fuel consumption $(0,99 \%)$, whereas Driver 11 achieved the most (20,95\%). Driver 12 only achieved an increase of $0,30 \%$. Also, a lower overall fuel consumption was determined for all the drivers after the training, with an average saving in fuel consumption by $8,61 \%$. The results showed that eco-driving techniques contributed to reducing parameters FCM (fuel consumption - on the move), TFC (total fuel consumption) and AFC (average fuel consumption) considerably and values of these parameters before training were significantly greater than those after training, $p=0,000, p=0,001$ and $p=0,001$, respectively. There are previous evidences which have also reported eco-driving training to result in an increase in fuel savings for bus drivers [9, 10, 23, 24, 25]. These researchers showed that eco-driving could increase the fuel economy up to $27 \%$.

Consequently, the average $\mathrm{CO}_{2}$ emission in tested drivers was reduced from $0,13 \%$ to $19,95 \%$ in relation to the emission before training. Average reduction in $\mathrm{CO}_{2}$ emission for all thirteen drivers was 8,61\%. Results showed that Eco-driving program significantly affected the reduction of average $\mathrm{CO}_{2}$ emission after training, $p=$ 0,001. Barić, Zovak and Periša [26] showed it was possible to achieve even higher emission reduction, of up to $32 \%$.

Result analysis after the eco-driving training in tested drivers (in Tab. 3) showed that nine drivers reduced the parameter APGP (the average accelerator pedal position) avoiding strong accelerations indicating that eco-driving training affected a significant improvement of this parameter after training, $p=0,009$. Pushing the throttle not more than $50 \%$ can be beneficial for fuel economy [27]. After eco-driving training, nine drivers increased the time of driving without throttle while the vehicle was in motion. 
The improvements are between range of $0,32 \%-49,49 \%$ while four drivers decreased between range of $3,38 \%$ $38,13 \%$. Post-training improvements were no statistically significant, $p=0,155$. In addition, there was no significant effect of the eco-driving training on increasing total distance with driving without throttle, $p=0,479$.

Table 2 Driving quality parameters before (D1) and after eco-driving training (D2)

\begin{tabular}{|c|c|c|c|c|c|c|c|c|c|}
\hline & \multicolumn{8}{|c|}{ Parameters } \\
\hline & & $\mathrm{D}$ & Dis & AS & ASM & FCM & TFC & $\mathrm{AFC}$ & $\mathrm{ACO}_{2}$ \\
\hline & & hh:mm:ss & $\mathrm{km}$ & $\mathrm{km} / \mathrm{h}$ & $\mathrm{km} / \mathrm{h}$ & L(litre) & L(litre) & $\mathrm{L} / 100 \mathrm{~km}$ & $\mathrm{~kg} / 100 \mathrm{~km}$ \\
\hline \multirow{3}{*}{$\begin{array}{l}\overrightarrow{\bar{s}} \\
\vec{\Delta} \\
\end{array}$} & D1 & $0: 25: 00$ & 14,34 & 34,42 & 37,08 & 7,89 & 8,13 & 56,7 & 150,7 \\
\hline & D2 & $0: 25: 50$ & 14,35 & 33,33 & 35,85 & 7,81 & 8,12 & 56,63 & 150,5 \\
\hline & $\%$ & 3,33 & 0,07 & $-3,17$ & $-3,31$ & $-1,01$ & $-0,12$ & $-0,12$ & $-0,13$ \\
\hline \multirow{3}{*}{$\begin{array}{l}\stackrel{N}{\Delta} \\
\stackrel{\vec{D}}{\vec{D}} \\
\end{array}$} & D1 & $0: 25: 52$ & 14,39 & 33,38 & 35,09 & 8,04 & 8,25 & 57,3 & 152,5 \\
\hline & D2 & $0: 30: 19$ & 14,39 & 28,48 & 30,25 & 7,96 & 8,23 & 57,16 & 152,2 \\
\hline & $\%$ & 17,20 & 0,00 & $-14,67$ & $-13,8$ & $-0,99$ & $-0,24$ & $-0,24$ & $-0,19$ \\
\hline \multirow{3}{*}{$\begin{array}{l}m \\
\dot{D} \\
\stackrel{n}{\vec{D}}\end{array}$} & D1 & $0: 26: 55$ & 14,34 & 31,98 & 35,01 & 7,9 & 8,28 & 57,7 & 153,6 \\
\hline & D2 & $0: 29: 27$ & 14,34 & 29,21 & 32,1 & 7,58 & 7,81 & 57,43 & 144,9 \\
\hline & $\%$ & 9,41 & 0,00 & $-8,66$ & $-8,31$ & $-4,05$ & $-5,67$ & $-0,47$ & $-5,66$ \\
\hline \multirow{3}{*}{$\begin{array}{l}\stackrel{+}{\Delta} \\
\stackrel{\vec{D}}{\vec{D}} \\
\end{array}$} & D1 & $0: 28: 46$ & 14,38 & 30,00 & 32,35 & 8,82 & 9,09 & 63,2 & 168,1 \\
\hline & D2 & $0: 26: 42$ & 14,33 & 32,19 & 33,11 & 7,42 & 7,53 & 52,36 & 139,7 \\
\hline & $\%$ & $-7,18$ & $-0,35$ & 7,30 & 2,35 & $-15,87$ & $-17,16$ & $-17,16$ & $-16,89$ \\
\hline \multirow{3}{*}{ 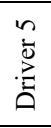 } & D1 & $0: 27: 18$ & 14,35 & 31,53 & 33,57 & 7,92 & 8,16 & 56,9 & 151,3 \\
\hline & D2 & $0: 28: 39$ & 14,33 & 30,00 & 32,88 & 7,33 & 7,73 & 53,9 & 143,5 \\
\hline & $\%$ & 4,97 & $-0,11$ & $-4,84$ & $-2,03$ & $-7,48$ & $-5,31$ & $-5,20$ & $-5,20$ \\
\hline \multirow{3}{*}{$\begin{array}{l}0 \\
\stackrel{\vec{D}}{0} \\
\stackrel{\vec{D}}{0}\end{array}$} & D1 & $0: 30: 02$ & 14,27 & 28,51 & 30,49 & 7,5 & 7,84 & 54,94 & 145,1 \\
\hline & D2 & $0: 30: 43$ & 14,18 & 27,7 & 29,32 & 6,42 & 6,72 & 47,4 & 126,1 \\
\hline & $\%$ & 2,30 & $-0,63$ & $-2,92$ & $-3,84$ & $-14,39$ & $-14,20$ & $-15,91$ & $-15,07$ \\
\hline \multirow{3}{*}{ 离 } & D1 & $0: 27: 47$ & 14,54 & 31,41 & 33,80 & 6,61 & 6,78 & 46,6 & 124,0 \\
\hline & D2 & $0: 27: 35$ & 14,55 & 31,64 & 32,81 & 6,47 & 6,57 & 45,2 & 120,2 \\
\hline & $\%$ & $-0,54$ & 0,03 & 0,73 & $-2,95$ & $-2,25$ & $-3,05$ & $-3,08$ & $-3,08$ \\
\hline \multirow{3}{*}{$\begin{array}{l}\infty \\
\vec{D} \\
\vec{D}\end{array}$} & D1 & $0: 31: 26$ & 14,33 & 27,36 & 29,11 & 8,44 & 8,70 & 60,7 & 161,4 \\
\hline & D2 & $0: 25: 27$ & 14,36 & 33,85 & 36,14 & 7,25 & 7,37 & 51,3 & 136,5 \\
\hline & $\%$ & $-19,03$ & 0,20 & 23,70 & 24,18 & $-14,07$ & $-15,23$ & $-15,40$ & $-15,40$ \\
\hline \multirow{3}{*}{$\begin{array}{l}a \\
\vec{\Delta} \\
\vec{D}\end{array}$} & D1 & $0: 27: 13$ & 14,16 & 31,21 & 33,25 & 7,69 & 7,96 & 56,2 & 149,5 \\
\hline & D2 & $0: 22: 26$ & 14,28 & 38,19 & 39,26 & 7,12 & 7,22 & 50,5 & 134,4 \\
\hline & $\%$ & $-17,54$ & 0,91 & 22,37 & 18,07 & $-7,40$ & $-9,29$ & $-10,14$ & $-10,11$ \\
\hline \multirow{3}{*}{$\begin{array}{l}\circ \\
\stackrel{0}{0} \\
\stackrel{D}{D} \\
\stackrel{D}{0}\end{array}$} & D1 & $0: 24: 17$ & 14,40 & 35,57 & 37,84 & 8,91 & 9,09 & 63,1 & 167,9 \\
\hline & D2 & $0: 25: 49$ & 14,40 & 33,47 & 35,10 & 7,43 & 7,63 & 53,0 & 141,0 \\
\hline & $\%$ & 6,29 & 0,00 & $-5,90$ & $-7,23$ & $-16,66$ & $-15,98$ & $-15,99$ & $-16,02$ \\
\hline \multirow{3}{*}{$\begin{array}{l}\vec{J} \\
\vec{\Delta} \\
\stackrel{\vec{\Delta}}{\Delta}\end{array}$} & D1 & $0: 24: 40$ & 14,37 & 34,95 & 36,06 & 9,30 & 9,39 & 65,4 & 173,8 \\
\hline & D2 & $0: 27: 33$ & 14,33 & 31,21 & 32,21 & 7,35 & 7,50 & 52,3 & 139,2 \\
\hline & $\%$ & 11,68 & $-0,29$ & $-10,72$ & $-10,68$ & $-20,95$ & $-20,18$ & $-19,95$ & $-19,95$ \\
\hline \multirow{3}{*}{ 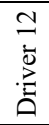 } & D1 & $0: 25: 31$ & 14,26 & 33,54 & 36,69 & 7,32 & 7,60 & 53,3 & 141,7 \\
\hline & D2 & $0: 26: 44$ & 14,26 & 32,01 & 34,24 & 7,34 & 7,56 & 53,0 & 141,0 \\
\hline & $\%$ & 4,78 & 0,00 & $-4,55$ & $-6,68$ & 0,30 & $-0,47$ & $-0,48$ & $-0,49$ \\
\hline \multirow{3}{*}{$\stackrel{m}{\stackrel{m}{\vec{D}}}$} & D1 & $0: 33: 15$ & 14,29 & 25,79 & 28,95 & 8,43 & 8,81 & 61,7 & 164,1 \\
\hline & D2 & $0: 35: 19$ & 14,29 & 24,27 & 28,24 & 7,82 & 8,36 & 58,5 & 155,6 \\
\hline & $\%$ & 6,22 & 0,00 & $-5,87$ & $-2,45$ & $-7,25$ & $-5,18$ & $-5,16$ & $-5,16$ \\
\hline
\end{tabular}

Note: D - Duration; DIS - Distance; AS - Average speed; ASM - Average speed - on the move; FCM - Fuel consumption - on the move; TFC - Total fuel consumption; AFC - Average fuel consumption; $\mathrm{ACO}_{2}-$ Average $\mathrm{CO}_{2}$ emission

After applying advices on reducing the risky traffic situations the drivers were given during their training, ten drivers reduced their brake time during driving after ecodriving training from $3,53 \%$ to $70,15 \%$. After the training these ten drivers used the brake less between range of $36,84 \%-86,60 \%$ which consequently led to an increased fuel economy. Eco-driving program was effective in these two parameters, BT (brake time) and BC (brake count), so it was statistically shown that their values before training were greater than those of after training, $p=0,004$ and $p=$ 0,003 , respectively. These findings were justified by previous researches $[5,28]$, claiming that a large number of sudden breakings could be responsible for the increase of the fuel consumption by around $30-44 \%$ in comparison to vehicles that were driving smoothly and moderately.

After eco-driving training, the stopping events count reduced, as statistically demonstrated, $p=0,007$. When faced with situations where the drivers had to stop (e.g. at intersections), these drivers anticipated the traffic situations enabling a more comfortable and safer drive without sudden braking. 
Table 3 Analysis of results of the tested drivers before (D1) and after eco-driving training (D2)

\begin{tabular}{|c|c|c|c|c|c|c|c|c|c|c|c|}
\hline & & \multicolumn{10}{|c|}{ Parameters } \\
\hline & & APGP & DWTM & BT & DWTTD & BUTD & $\mathrm{BC}$ & SEC & IT & $\mathrm{GC}$ & AES \\
\hline & & $\%$ & $\mathrm{~mm}: \mathrm{ss}$ & mm:ss & $\mathrm{km}$ & $\mathrm{km}$ & $\#$ & $\#$ & mm:ss & $\#$ & rpm \\
\hline \multirow{3}{*}{$\begin{array}{l}\overrightarrow{\bar{\Delta}} \\
\vec{\Delta} \\
\vec{\Delta}\end{array}$} & D1 & 30,00 & 05:09 & 01:07 & 3,13 & 0,17 & 20 & 6 & 01:48 & 88 & 1077 \\
\hline & D2 & 26,00 & $05: 10$ & $01: 51$ & 2,85 & 0,13 & 20 & 8 & $01: 49$ & 89 & 1021 \\
\hline & $\%$ & $-13,13$ & 0,32 & 41,12 & $-8,94$ & $-23,53$ & 0,00 & 33,33 & 0,92 & 1,14 & $-5,19$ \\
\hline \multirow{3}{*}{$\stackrel{\sim}{\sim}$} & D1 & 30,00 & $04: 30$ & 01:18 & 2,56 & 0,19 & 26 & 2 & $01: 16$ & 95 & 1072 \\
\hline & D2 & 25,00 & $06: 18$ & $01: 49$ & 3,28 & 0,15 & 34 & 3 & $01: 46$ & 104 & 1045 \\
\hline & $\%$ & $-16,67$ & 40,00 & 26,27 & 28,12 & $-21,05$ & 30,77 & 50,00 & 39,47 & 9,47 & $-2,52$ \\
\hline \multirow{3}{*}{$\stackrel{m}{\stackrel{m}{\Delta}}$} & D1 & 28,00 & $04: 13$ & $03: 18$ & 2,36 & 0,22 & 19 & 9 & $02: 20$ & 96 & 1034 \\
\hline & D2 & 25,00 & $06: 14$ & 03:11 & 3,25 & 0,07 & 12 & 7 & $02: 39$ & 99 & 1015 \\
\hline & $\%$ & $-10,71$ & 47,83 & $-3,53$ & 37,71 & $-68,18$ & $-36,84$ & $-22,22$ & 13,57 & 3,12 & $-1,84$ \\
\hline \multirow{3}{*}{ 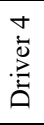 } & D1 & 28,00 & 07:39 & $03: 21$ & 4,5 & 0,17 & 26 & 9 & 02:05 & 144 & 1054 \\
\hline & D2 & 28,00 & $04: 44$ & 01:00 & 2,57 & 0,04 & 9 & 4 & $00: 44$ & 68 & 1046 \\
\hline & $\%$ & 0,00 & $-38,13$ & $-70,15$ & $-42,89$ & $-76,47$ & $-65,38$ & $-55,55$ & $-64,80$ & $-52,78$ & $-0,76$ \\
\hline \multirow{3}{*}{ 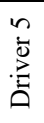 } & D1 & 28,00 & 06:04 & $02: 45$ & 3,41 & 0,19 & 24 & 9 & 01:39 & 102 & 1038 \\
\hline & D2 & 25,00 & $05: 17$ & 02:06 & 2,77 & 0,13 & 14 & 6 & $02: 31$ & 71 & 1025 \\
\hline & $\%$ & $-9,09$ & $-12,91$ & $-23,74$ & $-18,79$ & $-32,87$ & $-43,75$ & $-33,33$ & 51,70 & $-30,39$ & $-1,22$ \\
\hline \multirow{3}{*}{ 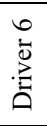 } & D1 & 23,00 & $08: 56$ & 02:01 & 5,32 & 0,28 & 51 & 11 & $01: 57$ & 125 & 1021 \\
\hline & D2 & 21,00 & $08: 24$ & $01: 30$ & 4,22 & 0,20 & 24 & 4 & $01: 42$ & 95 & 1002 \\
\hline & $\%$ & $-9,73$ & $-6,00$ & $-25,38$ & $-20,70$ & $-29,01$ & $-52,48$ & $-63,64$ & $-12,94$ & $-24,00$ & $-1,84$ \\
\hline \multirow{3}{*}{$\stackrel{\vec{D}}{\vec{D}}$} & D1 & 24,00 & 05:04 & 01:09 & 2,74 & 0,10 & 13 & 6 & 01:58 & 86 & 1014 \\
\hline & D2 & 24,00 & $06: 20$ & $01: 16$ & 3,63 & 0,11 & 18 & 3 & $00: 59$ & 100 & 1014 \\
\hline & $\%$ & 0,00 & 24,79 & 9,07 & 32,52 & 15,82 & 38,46 & $-50,00$ & $-50,10$ & 16,28 & 0,00 \\
\hline \multirow{3}{*}{$\begin{array}{l}\infty \\
\dot{\vec{\Delta}} \\
\dot{\vec{\Delta}}\end{array}$} & D1 & 26,00 & $04: 45$ & $02: 57$ & 2,39 & 0,18 & 28 & 10 & 01:53 & 130 & 1013 \\
\hline & D2 & 28,00 & $04: 54$ & 01:08 & 2,86 & 0,09 & 10 & 3 & $01: 37$ & 76 & 1056 \\
\hline & $\%$ & 8,45 & 3,14 & $-61,48$ & 19,86 & $-49,10$ & $-64,29$ & $-70,00$ & $-14,07$ & $-41,54$ & 4,25 \\
\hline \multirow{3}{*}{$\stackrel{a}{\overrightarrow{0}}$} & D1 & 27,00 & $04: 26$ & $02: 04$ & 2,56 & 0,05 & 10 & 6 & $01: 40$ & 76 & 1032 \\
\hline & D2 & 30,00 & $04: 58$ & $00: 57$ & 3,06 & 0,07 & 6 & 2 & $00: 37$ & 65 & 1088 \\
\hline & $\%$ & 9,57 & 12,00 & $-53,55$ & 19,79 & 43,82 & $-40,00$ & $-66,67$ & $-63,35$ & $-14,47$ & 5,39 \\
\hline \multirow{3}{*}{ 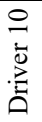 } & D1 & 36,00 & $06: 45$ & $02: 50$ & 4,52 & 0,48 & 49 & 6 & $01: 27$ & 101 & 1116 \\
\hline & D2 & 29,00 & $06: 32$ & $01: 24$ & 3,68 & 0,02 & 7 & 3 & $01: 12$ & 86 & 1069 \\
\hline & $\%$ & $-19,98$ & $-3,38$ & $-50,77$ & $-18,57$ & $-94,99$ & $-86,60$ & $-50,00$ & $-17,59$ & $-14,85$ & $-4,16$ \\
\hline \multirow{3}{*}{ 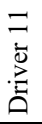 } & D1 & 36,00 & $07: 14$ & 02:07 & 4,72 & 0,26 & 25 & 5 & $00: 45$ & 106 & 1109 \\
\hline & D2 & 26,00 & $07: 21$ & $00: 45$ & 3,97 & 0,03 & 4 & 3 & $00: 51$ & 84 & 1056 \\
\hline & $\%$ & $-27,93$ & 1,76 & $-64,46$ & $-16,00$ & $-88,78$ & $-85,71$ & $-40,00$ & 13,37 & $-20,75$ & $-4,73$ \\
\hline \multirow{3}{*}{$\begin{array}{l}\stackrel{\sim}{J} \\
\stackrel{\vec{D}}{D} \\
\stackrel{D}{D}\end{array}$} & D1 & 28,00 & $04: 23$ & $02: 24$ & 2,53 & 0,12 & 27 & 4 & $02: 12$ & 82 & 1036 \\
\hline & D2 & 25,00 & 06:33 & 01:58 & 3,70 & 0,12 & 16 & 7 & 01:44 & 104 & 1041 \\
\hline & $\%$ & $-8,62$ & 49,49 & $-17,91$ & 46,12 & 0,00 & $-39,62$ & 75,00 & $-20,66$ & 26,83 & 0,49 \\
\hline \multirow{3}{*}{ 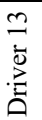 } & D1 & 24,00 & $04: 47$ & $05: 30$ & 2,26 & 0,25 & 48 & 13 & 03:38 & 113 & 1005 \\
\hline & $\mathrm{D} 2$ & 21,00 & 06:06 & 04:19 & 3,35 & 0,07 & 19 & 11 & 04:58 & 106 & 954 \\
\hline & $\%$ & $-13,60$ & 27,84 & $-21,60$ & 48,27 & $-72,76$ & $-60,00$ & $-15,38$ & 36,60 & $-6,19$ & $-5,05$ \\
\hline
\end{tabular}

Note: APGP - Average position of gas pedal; DWTM - Driving without throttle - moving time; BT - Brake time; DWTTD - Driving without throttle total distance; BUTD - Brake usage - total distance; BC - Brake count; SEC - Stopping events count; IT - Idling time; GSC - Gearshitf count; AES Average engine speed

A number of gear changes after the training reduced by eight drivers between range of $6,19 \%-52,78 \%$ while the five drivers increased between range of $1,14 \%-26,83 \%$. After eco-driving training, smoother driving was achieved as statistically demonstrated, $p=0,036$. Symmons, Rose \& van Doorn [29] claim that a decrease in the number of gear changes and the use of brake not only has a positive effect on reduction of risky situations, but also has a positive effect on the vehicle repair and maintenance expenses. Basarić et al. [10] moreover showed that a lower number of gear changes and smoother drive reduced the vehicle's wear and tear.

Although the improvements of the average engine speed were achieved to nine drivers when compared to the drive before the training, between range of $0,76 \%-5,19 \%$, the results among thirteen drivers revealed that there was no significant effect of the eco-driving training, $p=0,080$.

After eco-driving training seven drivers reduced the idling time from $12,94 \%$ to $64,80 \%$ while six drivers increased between range of $0,92 \%-51,70 \%$. The result among the thirteen drivers showed that there was no significant effect of the eco-driving training on reducing the vehicle's idle time, $p=0,300$. Researchers have shown that idling time is the most inefficient use of fuel [12]. Natural Resources Canada [30] have concluded that the idling time of the vehicle of more than 10 seconds has a higher fuel consumption than turning the engine off and starting it again.

Tab. 4 summarized the outcome of the eco-driving training and it disclosed that there was a general improvement in the driver's manner of driving. 


\begin{tabular}{|c|c|c|c|c|c|}
\hline Driving Parameters & Units & Mean & SD & $\mathrm{P}$-value & T-value \\
\hline $\mathrm{D}(\mathrm{D} 1)$ - D (D2) & $\mathrm{h}$ & $-0,0058$ & 0,0498 & 0,680 & $-0,42$ \\
\hline AS (D1) - AS (D2) & $\mathrm{km} / \mathrm{h}$ & 0,315 & 3,574 & 0,756 & 0,32 \\
\hline ASM (D1) - ASM (D2) & $\mathrm{km} / \mathrm{h}$ & 0,598 & 3,494 & 0,548 & 0,62 \\
\hline FCM (D1) - FCM (D2) & L(litre) & 0,758 & 0,609 & $0,000^{* *}$ & 4,49 \\
\hline TFC (D1) - TFC (D2) & L(litre) & 0,748 & 0,651 & $0,001^{* *}$ & 4,15 \\
\hline $\mathrm{AFC}(\mathrm{D} 1)-\mathrm{AFC}(\mathrm{D} 2)$ & $\mathrm{L} / 100 \mathrm{~km}$ & 5,00 & 4,70 & $0,001^{* *}$ & 3,84 \\
\hline $\mathrm{ACO}_{2}(\mathrm{D} 1)-\mathrm{ACO}_{2}$ (D2) & $\mathrm{kg} / 100 \mathrm{~km}$ & 13,76 & 11,90 & $0,001^{* *}$ & 4,17 \\
\hline APGP (D1) - APGP (D2) & $\%$ & 2,692 & 3,521 & $0,009^{* *}$ & 2,76 \\
\hline DWTM (D1) - DWTM (D2) & $\mathrm{h}$ & $-0,00675$ & 0,02294 & 0,155 & $-1,06$ \\
\hline BT (D1) - BT (D2) & $\mathrm{h}$ & 0,01327 & 0,01533 & $0,004^{* *}$ & 3,12 \\
\hline DWTTD (D1) - DWTTD (D2) & $\mathrm{km}$ & $-0,015$ & 0,992 & 0,479 & $-0,05$ \\
\hline BUTD (D1) - BUTD (D2) & $\mathrm{km}$ & 0,1100 & 0,1294 & $0,005^{* *}$ & 3,07 \\
\hline $\mathrm{BC}(\mathrm{D} 1)-\mathrm{BC}(\mathrm{D} 2)$ & \# & 13,31 & 14,32 & $0,003^{* *}$ & 3,35 \\
\hline SEC (D1) - SEC (D2) & $\#$ & 2,462 & 3,072 & $0,007^{* *}$ & 2,89 \\
\hline IT (D1) - IT (D2) & $\mathrm{h}$ & 0,00190 & 0,01275 & 0,300 & 0,54 \\
\hline GC (D1) - GC (D2) & \# & 15,15 & 27,72 & $0,036^{* *}$ & 1,97 \\
\hline AES (D1) - AES (D2) & $\mathrm{rpm}$ & 14,54 & 35,00 & 0,080 & 1,50 \\
\hline
\end{tabular}

Note: Driving parameters were calculated as (D1) minus (D2); **significant P-value at $5 \%$ level; SD: Standard Deviation

\subsection{Eco-Driving}

Assessment of the fuel economy provides the calculation of the economic benefits for the public transport company "JGSP Belgrade", from implementing eco-driving education among its drivers. In this company, the overall structure costs of $32 \%$ go to fuel expenses. Every bus consumes around 228291 of diesel annually, which indicates that an average fuel saving of $8,61 \%$ results in an annual saving of 19661 of diesel fuel per bus. If an average price for 11 of diesel fuel is $€ 0,90$, than an annual saving for each bus would be $€ 1769$ amounting to $€ 1487729$ for the 841 bus fleet. Symmons et al. [29] established that if a car fleet consuming around 1,5 million litters of diesel fuel per year saved just $1 \%$, it would made the savings of $\$ 15000$ per annum.

\section{CONCLUSIONS}

In this paper, the effectiveness of Eco-driving training in the public transport company "JGSP Belgrade", Serbia, was investigated. The results confirm the findings of the previous researches that Eco-driving training reduces fuel consumption, $\mathrm{CO}_{2}$ emissions, and improves driver behaviour short-term. In the present pilot program fuel economy was enhanced on average by $8,61 \%$ after the training and hence the average $\mathrm{CO}_{2}$ emission was reduced by $8,61 \%$. Furthermore, the findings of this pilot program also demonstrated that eco-driving training has the potential to significantly reduce fuel-related costs for transport companies.

Eco-driving effects have shown a general improvement in the driver's manner of driving. However, some driving parameters (D, AS, ASM, DWTM, DWTTD, IT, AES) were not significantly improved after training indicating a driver's slow adaptation and application of new driving techniques. Therefore, eco-driving program needs to examine how the guidelines for these driving parameters could be improved.

Although our results were enticed under realistic conditions with potentially a great validity, this study had limitations that should be accepted in the context of the results. One limitation was the small sample size $(N=13)$ and it may not be possible to generalize the findings to other companies without restrictions. However, these findings can provide a preliminary access into what level of influence an eco-driving training and education can have on bus drivers' fuel efficiency. Furthermore, the primary goal of drivers is not to save fuel but to take passengers to the destination site; drivers might not react to the interventions as drivers with other primary goals in different settings. There may be other external influences outside of our control which may distract the effects.

Future researches should test if, and to what extent, these results could be sustainable over a longer period, and whether they could be transferred to other domains of energy-efficiency behaviour.

\section{REFERENCES}

[1] Dhaou, I. B. (2011). Fuel Estimation Model for ECODriving and ECO-Routing. IEEE Inteligent Vehicles Symposium (IV), Baden-Baden, Germany, 37-42.

[2] Zhou, M., Jin, H., \& Wang, W. (2016). A review of vehicle fuel consumption models to evaluate eco-driving and ecorouting. Transportation Research Part D: Transport and Environment, 49, 203-218. https://doi.org/10.1016/j.trd.2016.09.008

[3] Lee, I. M., Lee, S., Park, J. S., \& Do Kim, S. (2012). Area Wide Calculation of Traffic Induced $\mathrm{CO}_{2}$ Emission in Seoul. KSCE Journal of Civil Engineering, 16(3), 450-456. https://doi.org/10.1007/s12205-012-1525-5

[4] McKinnon, A. C. \& Piecyk, M. I. (2009). Measurement of $\mathrm{CO}_{2}$ emissions from road freight transport: A review of UK experience. Energy Policy, 37, 3733-3742. https://doi.org/10.1016/j.enpol.2009.07.007

[5] Ericsson, E. (2001). Independent driving pattern factors and their influence on fuel use and exhaust emission factors. Transportation Research Part D: Transport and Environment, 6(5), 325-345. https://doi.org/10.1016/S1361-9209(01)00003-7

[6] Van Mierlo, J., Maggetto, G., van de Burgwal, E., \& Gense, R. (2004). Driving style and traffic measures - Influence on vehicle emissions and fuel consumption. Proceedings of the Institution of Mechanical Engineers, Part D: Journal of Automobile Engineering, 218(1), 43-50. https://doi.org/10.1243/095440704322829155

[7] Larusdottir, E. B. \& Ulfarsson, G. F. (2015). Effect of Driving behavior and Vehicle Characteristics on Energy Consumption of Road Vehicles Running on Alternative Energy Sources Effect of Driving behavior and Vehicle Characteristics on Energy Consumption of Road Vehicles 
Running on Alternative Energy. International Journal of Sustainable Transportation, 9, 592-601. https://doi.org/10.1080/15568318.2013.843737

[8] Barkenbus, J. N. (2010). Eco-driving: An overlooked climate change initiative. Energy Policy, 38(2), 762-769. https://doi.org/10.1016/j.enpol.2009.10.021

[9] Zarkadoula, M., Zoidis, G., \& Tritopoulou, E. (2007) Training urban bus drivers to promote smart driving: A note on a Greek eco-driving pilot program. Transportation Research Part D: Transport and Environment, 12(6), 449451. https://doi.org/10.1016/j.trd.2007.05.002

[10] Basarić, V., Jambrović, M., Miličić, M., Savković, T., Basarić, Đ., \& Bogdanović, V. (2017). Positive Effects of Eco-Driving in Public Transport - A Case Study of the City Novi Sad. Thermal Science, 21(1B), 683-692. https://doi.org/10.2298/TSCl150219160B

[11] Ho, S., Wong, Y., \& Chang, V. W. (2015). What can ecodriving do for sustainable road transport? Perspectives from a city (Singapore) eco-driving programme. Sustainable Cities and Society, 14, 82-88. https://doi.org/10.1016/j.scs.2014.08.002

[12] Rutty, M., Matthews, L., Andrey, J., \& Del Matto, T. (2013). Eco-driver training within the City of Calgary's municipal fleet : Monitoring the impact. Transportation Research Part D: Transport and Environment, 24, 44-51. https://doi.org/10.1016/j.trd.2013.05.006

[13] Haworth, N. \& Symmons, M. (2001). The Relationship between Fuel Economy and Safety Outcomes. Report No. 188, Monash University Accident Research Centre. Australia.

[14] SenterNovem. (2005). Ecodriving: The smart driving style. TREATISE project, pp. 31. Utrecht.

[15] Beusen, B., Broekx, S., Denys, T., Beckx, C., Degraeuwe, B., Gijsbers, M., et al. (2009). Using on-board logging devices to study the long-term impact of an eco-driving course. Transportation Research Part D: Transport and Environment, 14(7), 514-520. https://doi.org/10.1016/j.trd.2009.05.009

[16] Siero, S., Boon, M., Kok, G., \& Siero, F. (1989). Modification of driving behavior in a large transport organization: A field experiment. Journal of Applied Psychology, 74(3), 417-423. https://doi.org/10.1037/0021-9010.74.3.417

[17] Dogan, E., Steg, L., \& Delhomme, P. (2011). The influence of multiple goals on driving behavior: The case of safety, time saving, and fuel saving. Accident Analysis and Prevention, 43(5), 1635-1643. https://doi.org/10.1016/j.aap.2011.03.002

[18] Delhomme, P., Paran, F., \& Nikolas, P. A. (2010). Ecodriving with Eco-cognition: development of cognitive indicators, Experimental design. Report on the Convention with the KOTSA Institute. Korea.

[19] Yang, X. Y., Li, D. \& Zheng, P. J. (2012). Effects of Ecodriving on Driving Performance. Applied Mechanics and Materials, 178-181, 2859-2862. https://doi.org/10.4028/www.scientific.net/AMM.178-181.2859

[20] Sullman, M. J. M., Dorn, L., \& Niemi, P. (2015). Ecodriving training of professional bus drivers - Does it work? Transportation Research Part C: Emerging Technologies, 58, 749-759. https://doi.org/10.1016/j.trc.2015.04.010

[21] Van den Hoed, R., Harmelink, M., \& Joosen, S. (2006) Evaluation of the Dutch Eco-Driving Programme, in frame of AID-EE project-Active Implementation of the European Directive on Energy Efficiency, European Commission, Retrieved June 10, 2018, from: https://www.ecofys.com/ files/files/aid-ee-2006-evaluation-ecodrive-netherlands.pdf

[22] International Energy Agency, IEA. (2008). Energy Policies of IEA Countries. Review, Japan.

[23] Carrese, S., Gemma, A., \& La Spada, S. (2013). Impacts of Driving Behaviours, Slope and Vehicle Load Factor on Bus
Fuel Consumption and Emissions: A Real Case Study in the City of Rome. Procedia - Social and Behavioral Sciences, 87(10), 211-221. https://doi.org/10.1016/j.sbspro.2013.10.605

[24] Huertas, J. I., Díaz, J., Giraldo, M., Cordero, D., \& Tabares, L. M. (2018). Eco-driving by replicating best driving practices. International Journal of Sustainable Transportation, 12(2), 107-116. https://doi.org/10.1080/15568318.2017.1334107

[25] Strömberg, H. K. \& Karlsson, M. A. (2013). Comparative effects of eco-driving initiatives aimed at urban bus drivers - Results from a field trial. Transport Research Part D: Transport and Environment, 22, 28-33. https://doi.org/10.1016/j.trd.2013.02.011

[26] Barić, D., Zovak, G., \& Periša, M. (2013). Effects of ecodrive education on the reduction of fuel consumption and $\mathrm{CO}_{2}$ emissions. Promet - Traffic \& Transportation, 25(3), 265-272. https://doi.org/10.7307/ptt.v25i3.1260

[27] Johansson, H. (1999). Impact of Eco-driving on emissions and fuel consumption: A pre study. Publication No. 1999:169E. Swedish Road Administration. Borlange, Sweden.

[28] Saboohi, Y. \& Farzaneh, H. (2009). Model for developing an eco-driving strategy of a passenger vehicle based on the least fuel consumption. Applied Energy, 86(10), 1925-1932. https://doi.org/10.1016/j.apenergy.2008.12.017

[29] Symmons, M. A., Rose, G., \& Van Doorn, G. H. (2008). The effectiveness of an ecodrive course for heavy vehicle drivers. Australasian Road Safety Research, Policing and Education Conference, Adelaide, South Australia, 87-194.

[30] Natural Resources Canada. (2009). Idling Wastes Fuel and Money, Retrieved June 10, 2018, http://oee.nrcan.gc.ca/ transportation/idling/wastes.cfm?attr $=8$.

\section{Contact information:}

Tatjana SAVKOVIĆ, MSc.., PhD Candidate

University of Novi Sad,

Faculty of Technical Sciences,

Department of Traffic Engineering,

Trg Dositeja Obradovića 6, 21101 Novi Sad, Serbia

savkovic.t@uns.ac.rs

\section{Pavle GLADOVIĆ, PhD, Full Professor}

University of Novi Sad,

Faculty of Technical Sciences,

Department of Traffic Engineering,

Trg Dositeja Obradovića 6, 21101 Novi Sad, Serbia

anaipavle@gmail.com

\section{Milica MILIČIĆ, PhD, Associate Professor}

(Corresponding author)

University of Novi Sad,

Faculty of Technical Sciences,

Department of Traffic Engineering,

Trg Dositeja Obradovića 6, 21101 Novi Sad, Serbia mmilica@uns.ac.rs

\section{Pavle PITKA, PhD, Assistant Professor}

University of Novi Sad,

Faculty of Technical Sciences,

Department of Traffic Engineering,

Trg Dositeja Obradovića 6, 21101 Novi Sad, Serbia pitka@uns.ac.rs

\section{Sanja ILIĆ, BSc, Project Manager}

RICo Training Centre

Arčibalda Rajsa 27, 11000 Beograd, Serbia

rtccentar@gmail.com 